\title{
Quadros de referência para o desempenho dos líderes escolares ${ }^{4}$
}

\author{
Jorge Adelino Costa*
}

Sandra Figueiredo**

\section{Resumo}

0 reconhecimento da influência da liderança no desempenho docente e discente conduz à necessidade de compreender este tipo de práticas nos diversos sistemas educativos e retirar daí informação pertinente para melhorar as respostas educacionais. A eficácia é um dos conceitos emergentes neste domínio de investigação e surge associado à def inição de quadros de referência do desempenho dos líderes escolares. Com base numa incursão por documentos institucionais, bem como por dados de relatórios da OCDE, apresentamos uma síntese de quadros de referência para a liderança nas escolas em vários países. Os sistemas educativos selecionados apresentam práticas de liderança escolar tidas como positivas, que organizámos em seis dimensões: orientação estratégica, visão e missão; processo de ensino e aprendizagem (liderança instrucional/pedagógica); relações interpessoais e desenvolvimento; organização e gestão de recursos; prestação de contas e responsabilização; relações com comunidade e contextos.

Palavras-chave: Liderança educacional. Quadros de referência. Gestores escolares. OCDE.

\section{Performance frameworks for school leaders}

\section{Abstract}

The recognition of the influence of leadership on student and teacher performance leads to the need to understand this kind of practice in the various educational systems and to draw relevant information to improve the educational responses. Effectiveness is one of the emergent concepts in this area of research and is associated with the definition of frameworks for the school leader's performance. Based on institutional documents, as well as on OECD reports data, we present a synthesis of frameworks for leadership in schools in several countries. The selected educational systems exhibit school leadership practices perceived as

* Doutor e Agregado em Educação. Professor Catedrático da Universidade de Aveiro, Portugal.

E-mail:jcosta@ua.pt

** Doutora em Psicologia. Assistente de Investigação na Universidade de Aveiro, Portugal.

E-mail: sandradfigueiredo@ua.pt

4 Este trabalho é financiado por Fundos FEDER através do Programa Operacional Fatores de Competitividade - COMPETE e por Fundos Nacionais através da FCT - Fundação para a Ciência e a Tecnologia, no âmbito do projeto ELO - Educational Leadership Observatory (PTDC/CPE-CED/108655/2008). 
positive, which we have organized in six dimensions: strategic direction, vision and mission; teaching and learning process (instructional/pedagogical leadership); interpersonal relationships and development; organization and management of resources; accountability; relation to community and contexts.

Keywords: Educational leadership. Frameworks. School leaders. OECD.

\section{Marcos de referencia para el desempeño de los líderes escolares}

\section{Resumen}

El reconocimiento de la influencia del liderazgo en el desempeño docente y discente conduce hacia la necesidad de comprender este tipo de prácticas en los diversos sistemas educativos y extraer información relevante para mejorar las respuestas educativas. La eficacia es uno de los conceptos emergentes en este campo de investigación y surge asociado a la definición de los marcos de actuación de los líderes escolares. Basados en una incursión hecha en documentos institucionales así como en datos de los informes de la OCDE -Organización para la Cooperación y Desarrollo Económico, se presenta un panorama general de los marcos de liderazgo en las escuelas de varios países. Los sistemas educativos seleccionados presentan prácticas de liderazgo escolar que se consideran positivas, las cuales se organizaron en seis dimensiones: orientación estratégica, visión y misión; procesos de enseñanza y aprendizaje (liderazgo instruccional/pedagógico); relaciones interpersonales y desarrollo; organización y gestión de los recursos; rendición de cuentas y responsabilización; relaciones con la comunidad y contextos.

Palabras clave: Liderazgo educativo. Marcos de referencia. Gestores escolares. OCDE.

\section{Introdução}

Temos vindo a assistir, nos últimos anos, a um enfoque progressivo nas questões da liderança escolar, que assumem um interesse manifesto no quadro das propostas de qualificação das respostas escolares. Constata- se esta tendência, designadamente, nos estudos desenvolvidos pela OCDE (Organização para a Cooperação e Desenvolvimento Económico), organização que apresenta este novo interesse com base na necessidade de reportar dados válidos sobre 0 quadro de liderança escolar atualmente vigente em vários países, considerando que existe uma lacuna de conhecimento formal sobre este tipo de práticas. Os investigadores reconhecem a influência que a liderança exerce sobre os níveis de desempenho docente e discente, daí a necessidade de entender as práticas em vigor em diversos países da OCDE e captar informação pertinente para inovar e implementar medidas que conduzam à sua maior eficácia (eficácia entendida como satisfação na consecução dos objetivos propostos e, neste caso concreto, satisfação na consecução dos quadros de referência para liderança). 
Neste sentido, a OCDE vem, desde 2006, apresentando propostas de estudo e relatórios variados. Por exemplo, em 2007, foi divulgado um estudo (PONT; NUSCHE; M OORMAN et al., 2008a; 2008b) cujo objetivo consistiu em identificar e sintetizar práticas de liderança escolar de forma a facilitar a operacionalização de orientações inovadoras e modelos de intervenção. 0 estudo, delineado numa perspetiva transcultural, foi elaborado para apresentar casos de vinte e dois países que integram a OCDE. Os padrões europeus (e não só) referentes ao desempenho e funções dos líderes escolares foram identificados com base em autoavaliações e análises de práticas apresentadas pelos representantes de cada país, traduzido num estudo comparativo sobre liderança educacional. Posteriormente, em 2012, também um outro relatório e documento orientador da iniciativa da OCDE (Schleicher, 2012), fundamentado em casos tidos como eficazes (Reino Unido, Canadá e Áustria), aponta um conjunto de estratégias de ação neste domínio, tais como: a necessidade de uma abordagem inovadora e focada no uso das tecnologias, a importância de centrar os processos de liderança no desempenho discente e 0 alinhamento dos programas curriculares com os objetivos cruciais da escola (Schleicher, 2012, p. 22). A seleção destes casos (sistemas educativos de vários países) teve por base a análise de critérios considerados eficazes para o exercício da liderança, constituindo- se como principal diferenciador a relação da liderança com os resultados do ensino e da aprendizagem.

Neste quadro, um dos campos de intervenção que tem vindo a colher interesse crescente é 0 da importância estratégica que assume, para a ação, avaliação e supervisão dos líderes escolares, a definição de quadros de referência de liderança.

A construção deste tipo de documentos (quadros de referência/standards/padrões) para o exercício profissional teve a sua alavancagem, no contexto educacional, com a definição de padrões de desempenho de docente, no âmbito da implementação de políticas mais exigentes de avaliação de professores. Países como os Estados Unidos, a Inglaterra, o Canadá e a Austrália são exemplos de contextos onde esta orientação política e este campo de investigação manifestam alguma tradição. No caso português, a definição de padrões de desempenho docente foi objeto de formulação, em 2010, pelo Conselho Científico para a Avaliação de Professores, para efeitos de avaliação dos professores do sistema público de educação e ensino (TOMÁS; COSTA, 2011).

Porém, no que diz respeito, especificamente, à definição de padrões de liderança escolar, embora se trate de um assunto com crescente destaque também em alguns dos países mencionados, a situação é bem mais recente e menos abrangente. Estes quadros de referência, tidos como fundamentais para a definição da essência do cargo e das respetivas tarefas profissionais, permitirão uma ação mais sustentada, quer em termos concetuais, quer na sua vinculação a políticas e objetivos contextuais específicos, contribuindo para uma definição mais adequada dos processos de formação, seleção, avaliação e supervisão dos gestores escolares. 
Com o presente artigo, interessa-nos dar conta da dimensão semântica atribuída aos quadros de referência para a liderança escolar tomando por base as propostas apresentadas por vários países, em particular: Inglaterra, Canadá, E.U.A., Chile, Austrália e Nova Zelândia. Como fonte de informação, para além dos dados presentes em vários relatórios da $\mathrm{OCDE}$, a nossa pesquisa procurará fontes primárias através da consulta a websites governamentais e institucionais, recolhendo aí os documentos que possam identificar as opções políticas de cada um dos países neste domínio. Ou seja, os quadros de referência/padrões/standards sobre liderança escolar, entendidos como referentes orientadores das práticas de gestão e liderança nas escolas de determinado país, serão aqui considerados apenas na condição de estarem alocados a orientações e diretrizes de políticas educativas estatais (e não a contextos de abordagens teóricas e empíricas particulares).

\section{Quadros de referência: perspetivas do conceito}

Os quadros de referência tornaram-se uma tendência das políticas educativas para orientar o cumprimento mais eficaz dos objetivos educacionais, neste caso, dos objetivos de desempenho em liderança educacional.

Porém, deparamo-nos com um vasto conjunto de variantes do conceito que, considerando 0 corpus textual de vários relatórios da OCDE, podemos sintetizar nos seguintes exemplos: standards, approaches, broad areas, policy, key-elements, goals, roles, responsibilities, recommendations, guidelines, dimensions, frameworks. Para além disso, os quadros de referência da liderança surgem, em função dos contextos nacionais, com orientações políticas distintas: ora aparecem vinculados a diretrizes de teor apenas indicativo/sugerido, ora surgem concebidos como normas regulamentadoras, ora ainda como atributos do líder ('o que define o líder'), portanto, como caraterísticas do comportamento dos gestores educacionais. Ou seja, deparamo-nos com um extenso recurso vocabular (em função de diferentes sistemas educacionais), mas que, à partida, exibe um mesmo objetivo: designar parâmetros de comportamento para os líderes escolares. Numa forma perifrástica, 0 desempenho dos diretores e administradores escolares torna-se supervisionado (e avaliado) à luz de orientações pré-estabelecidas que, como veremos adiante, apresentam frequentemente pontos comuns entre os vários países analisados.

Porém, a determinação de parâmetros de desempenho em liderança não é consensual entre os especialistas quanto ao seu efeito orientador e positivo. Há autores que questionam a visão demasiado carismática e autocrática como é muitas vezes concebida a figura e as funções do líder em detrimento de uma conceção mais distribuída e democrática, como decorre da seguinte citação:

Alguns países estabeleceram padrões ou qualificações profissionais específicas para o ensino. Existem objeções ao 
uso de padrões. Alguns críticos defendem que padrões como os existentes no Reino Unido tendem a codificar um forma de liderança carismática, heroica, que é contrária à necessidade de uma liderança mais participativa e distribuída. Os críticos dos padrões estabelecidos pelo Interstate School Leaders Licensure Consortium (ISLLC) nos Estados Unidos acreditam igualmente que estes reforçam uma perspetiva da liderança que não é democrática e ignoram valores importantes para a escola. (PONT; NUSCHE; MORM AN, 2008a, p. 117).

Não obstante os alertas apontados sobre o modo como o assunto é implementado em alguns países, podendo constituir constrangimento ao desempenho de lideranças suportadas por modelos de gestão e imagens organizacionais da escola que se pretendam democráticos e participativos (COSTA, 2000; 2003), a definição de dimensões, tarefas, responsabilidades, perfis e modos de ação dos líderes escolares revela, de um modo geral, mais vantagens do que limitações:

Em primeiro lugar, tais quadros de referência são uma forma de estabelecer fronteiras e de tornar claro o que a liderança escolar não inclui. Os quadros de referência da liderança constituem uma base sólida para a profissão e podem constituir um ponto de referência chave tanto para os que estão a pensar ingressar na profissão, como para os que têm a responsabilidade de os recrutar. Em segundo lugar, quadros de referência que definem uma grande variedade de tarefas de liderança a nível da escola tornam claro que certas condições precisam de ser asseguradas para os líderes escolares poderem ter um desempenho eficaz. Como exemplo, podemos apontar o fato de os quadros de referência poderem ser uma base crucial para melhorar a relevância e eficácia da formação profissional e do desenvolvimento dos líderes escolares. Os quadros de referência podem ser um ponto de partida para o desenho de uma preparação e desenvolvimento profissional melhorado e consistente (PONT; NUSCHE; M OORM AN, p. 62).

Neste sentido, somos de opinião que não é a existência de quadros de referência para a liderança escolar que, por si só, torna o exercício dos líderes mais autocrático ou gestionário, mas sim o seu conteúdo específico, bem como as políticas que lhes subjazem e os regulamentam. Ou seja, entendemos, pelo contrário, que a definição por determinado país/estado/região daquilo que pretende que seja o desempenho dos diretores das suas escolas contribuirá para um desempenho mais esclarecido, uma formação e preparação em sintonia, e uma avaliação e supervisão correspondentes, diminuindo, assim, as margens de aleatoriedade, ainda que seja, naturalmente, de respeitar a flexibilidade necessária na adaptação a cada contexto. 


\section{Dois casos de liderança escolar invocados pela literatura: Inglaterra e Canadá}

Abunda a literatura publicada evidenciando os cenários favoráveis e as boas práticas da liderança britânica, designadamente nos vários relatórios da OCDE. Independentemente do maior ou menor grau de sucesso das políticas postas em prática neste contexto geográfico, é notório o interesse e o investimento políticoinstitucional aí colocado nas questões da liderança educacional. E, nesse sentido, não serão de estranhar as recomendações feitas sobre 0 assunto, como as apresentadas pela Price Waterhouse Coopers (2007), no sentido de se garantir uma "effective leadership" nas escolas de Inglaterra (e País de Gales). Neste relatório de 2007, a Price Waterhouse Coopers, indiciando limitações às práticas vigentes, insiste numa estratégia de proatividade no sentido de se criarem políticas educativas eficazes em liderança:

1) maior diversificação de modelos de liderança, num estilo proactivo e emergente, tendo em conta o desenvolvimento de um programa nacional que oriente as escolas na construção de novos modelos de liderança praticáveis e ajustados;

2) distribuição das responsabilidades (liderança distribuída) com base numa revisão de políticas e práticas ("inter alia"); revisão da legislação das escolas no que respeita à responsabilização, acrescida de mais formação e especialização em liderança;

3) revisão de dimensões e práticas das estruturas de gestão, ou seja, do modus operandi nas escolas;

4) políticas de "streamlining", revendo mecanismos atuais que tornem a comunicação mais fluida e menos burocrática;

5) qualificação e preparação de profissionais tendo em vista a sucessão bem planeada dentro das escolas;

6) adoção de uma nova abordagem em relação às qualificações e programas de liderança, sobretudo com ênfase na partilha de conhecimentos com profissionais de outros setores (multidisciplinaridade);

7) soluções e-learning como componente da abordagem presencial;

8) sistema de recompensas mais efetivo, compensando novos desempenhos, examinando melhor a distribuição dos salários e das suas diferenciações de acordo com cargos e funções;

9) promoção de boas relações e comunicações ("winning hearts and minds"), dando conta das vantagens de novos modelos de liderança e fomentando 0 aparecimento de 'talentos' no campo do recrutamento de líderes ("talent pool").

Estas recomendações são também dirigidas pelos autores (PRICE WATERHOUSE COOPERS, 2007) ao Department for Education and Skills (DfES) no sentido de serem incluídas nas suas estratégias políticas e planos de ação: 
1) o DfES deve disseminar e promover as informações de novos modelos, designadamente os materiais e modelos desenvolvidos pelo National College for School Leadership (NCSL), junto das escolas e entidades governamentais através de uma orientação com base em exemplos de boas práticas apropriadas a diferentes contextos;

2) O DfES deve criar um programa nacional liderado pela NCSL para encorajar e apoiar os líderes escolares, corpos governamentais e autoridades locais para estes desenvolverem novos modelos;

3) O DfES deve continuar a monitorizar e a avaliar a efetividade de diferentes modelos de liderança educacional à medida que estes se desenvolvem e amadurecem para que os modelos válidos sejam identificados e disseminados.

Também o Canadá, em particular o Estado do Ontário, surge bem conotado na literatura no que diz respeito ao investimento na liderança das escolas. Desde 2004 (SCHLEICHER, 2012) que se encontra em curso a "Ontario Leadership Strategy", uma medida que aponta cinco diretrizes para o desempenho dos líderes escolares:

1) definição de direção (orientação estratégica);

2) construção de relações e parcerias;

3) desenvolvimento organizacional;

4) liderança do programa instrucional;

5) responsabilização ("being accountable").

Trata-se de uma resposta à preparação de líderes que procura assegurar a sucessão na liderança, de forma equilibrada e saudável. A sucessão é, efetivamente, um dos problemas comuns e bastante abordado no Canadá e em Inglaterra. Estas diretrizes constituem padrões de liderança ("Ontario Leadership Framework") integrantes da estratégia política geral de liderança ("Ontario Leadership Strategy") com o objetivo de ser operacionalizada num período de três anos (2008-2011). No contexto dessa política educativa, a "Ontario Leadership Framework" (iniciada em 2006) é uma medida central e def ine as competências principais do desempenho de presidentese vice-presidentes das escolas, assim como procura regulamentar práticas de eficácia nas mesmas. Esta eficácia está sobretudo relacionada com o desempenho académico e as práticas de ensino e aprendizagem. Em 2012, uma nova secção foi adicionada à ref erida estratégia política de liderança escolar no Ontário: "Personal Leadership Resources" (INSTITUTE FOR EDUCATION LEADERSHIP, 2012, p. 12).

A articulação entre as instituições escolares e a comunidade científica é um dos aspetos a assinalar nas medidas de promoção das práticas de liderança escolar canadiana. Na Royal Roads University, o repositório "School of Leadership Studies" dá-nos conta dos trabalhos de investigação na área de liderança educacional, assim como do programa de Mestrado e dos cursos 
que se oferecem nesta área científica. 0 objetivo é "motivar, empoderar e inspirar os outros para a construção de organizações mais saudáveis, mais eficazes, com relações fortes que se tornou um factor essencial para atingir objetivos pessoais e institucionais" (ROYAL ROADS UNIVERSITY, [2012]). Também na Universidade de Toronto, o projeto "Learning From Leadership Project: The Connection Between Educational Leadership and Student Learning" tem como principal alvo analisar informação que evidencie a relação entre a liderança educacional, as condições da escola e a aprendizagem dos alunos. 0 projeto explora os vários tipos de liderança (considerados num leque essencial de três géneros: colaborativa, distribuída e partilhada) em curso nas escolas no sentido de fortalecer os processos de aprendizagem. Do mesmo modo, a Canadian Association of Principals apresenta uma medida relacionada com a liderança que importa destacar: "The Learning Partnership", iniciada em 2006, com o objetivo de diagnosticar alunos em risco. A estratégia é disponibilizar soluções e recursos num website, simultaneamente em inglês e francês, para que os gestores das escolas as possam considerar nos seus contextos pedagógicos e organizacionais.

Verifica-se, na consulta aos sites e relatórios que documentam as práticas de liderança nas escolas do Ontário e do Québec, que há aqui uma preocupação diferente do que ocorre em Inglaterra no que respeita à missão da escola e dos seus líderes. Em Inglaterra, os padrões de desempenho são estipulados com base numa racionalidade que conduz ao cumprimento de metas estabelecidas e constantemente revistas em programas da National College for School Leadership, ao passo que no Canadá, há estratégias definidas e padrões similares, mas com vista ao desenvolvimento de uma missão de escola colaborativa e satisf eita com o trabalho produzido, mais do que com a produtividade objetivada. Ou seja, neste caso, mais do que com a 'contagem' dos índices de produtividade de docentes e alunos, parece haver uma preocupação peculiar com o cumprimento das políticas educativas: "0 papel do gestor escolar é assegurar que os objetivos organizacionais são atingidose que as políticas e os procedimentos são seguidos" (YOUNG; GROGAN, 2008, p. 312).

Relativamente aos programas de "pre-service qualification" (SCHLEICHER, 2012, p. 26), são relativamente análogos nos vários cenários da OECD, tratando-se de programas de iniciação e de formação contínua para os líderes já em exercício em escolas. Em Ontário, tais programas foram incorporados nas estratégias nacionais definidas no âmbito da medida de aperfeiçoamento escolar e são geridos pelo "Principal's Qualification Program". O planeamento da formação, quer no Canadá quer em Inglaterra, prende-se com uma questão já anteriormente referida: a sucessão. É este o objetivo final da organização dos profissionais por fases de preparação e formação, com o Canadá a considerar os períodos de cinco/sete anos (como ótimos ou críticos) para a vigência e sucessão dos líderes pois, num período inferior, a missão da escola não terá sido solidamente instituída (SCHLEICHER, 2012). 


\section{Padrões de liderança numa análise comparativa em contextos da OCDE}

Conforme já referimos anteriormente, vários países têm vindo a constar de relatórios da OCDE como casos onde as questões da liderança escolar assumem destaque, tendo em conta a análise da sua eficácia. Um dos elementos com que nos deparamos nas políticas de liderança destes países é a definição institucional de quadros de referência para o desempenho dos líderes escolares e aos quais vamos prestar atenção neste ponto.

Casos como a Inglaterra, o Canadá, a Áustria e a Austrália surgem no trabalho de Pont, Nusche e M oorman (2008a, p. 5) como contextos que refletem esta aptidão, traduzida, segundo os autores, nas seguintes dimensões da função diretiva: 1

1) desenvolvimento da liderança distribuída visível em equipas bem definidas e com funções claras e operacionais;

2) criação de equipas de intervenção para contextos de baixa performance ou com problemas de rendimento académico (dirigidas a professores e alunos);

3) cultura de constante avaliação, com salas de aula abertas e sempre disponíveis para avaliação e monitorização;

4) adoção de um sistema de liderança sistémica, aproveitando as oportunidades para desenvolver colaboração com os recursos externos.

Também no recente relatório de Schleicher (2012), a Inglaterra, o Canadá e a Áustria são alguns dos casos selecionados pela OCDE como sendo sistemas referenciais no que respeita a práticas de liderança. Os programas institucionais de cada um destes países (Leadership Academy, na Áustria; Ontario School Leadership Framework, no Canadá; National Professional Qualification for Headship, em Inglaterra) são responsáveis pela definição de medidas que promovam a sustentabilidade da liderança.

Observando os quadros de referência presentes nos três casos (quadro 1), vemos que, de um modo geral, as dimensões apontadas estão em consonância, apesar de algumas diferenças lexicais. Aspetos como a liderança instrucional, a gestão das pessoas, o desenvolvimento organizacional, o diálogo com a comunidade, a "accountability" e a 'liderança estratégica' perpassam as três propostas. Esta última, identificada com conceitos como "strategic", "setting direction" ou "shaping the future (strategically)", encontra-se imbuída, nestes contextos geográficos, da noção de espírito visionário e carismático do líder. Por exemplo, em Inglaterra, Pont, Nusche e Moorman (2008a, p. 61) referem- se à missão do líder como, simultaneamente, o guia da comunidade e 0 'expert leader'. 
Quadro 1 - Dimensões dos quadros de referência para o desempenho dos líderes escolares.

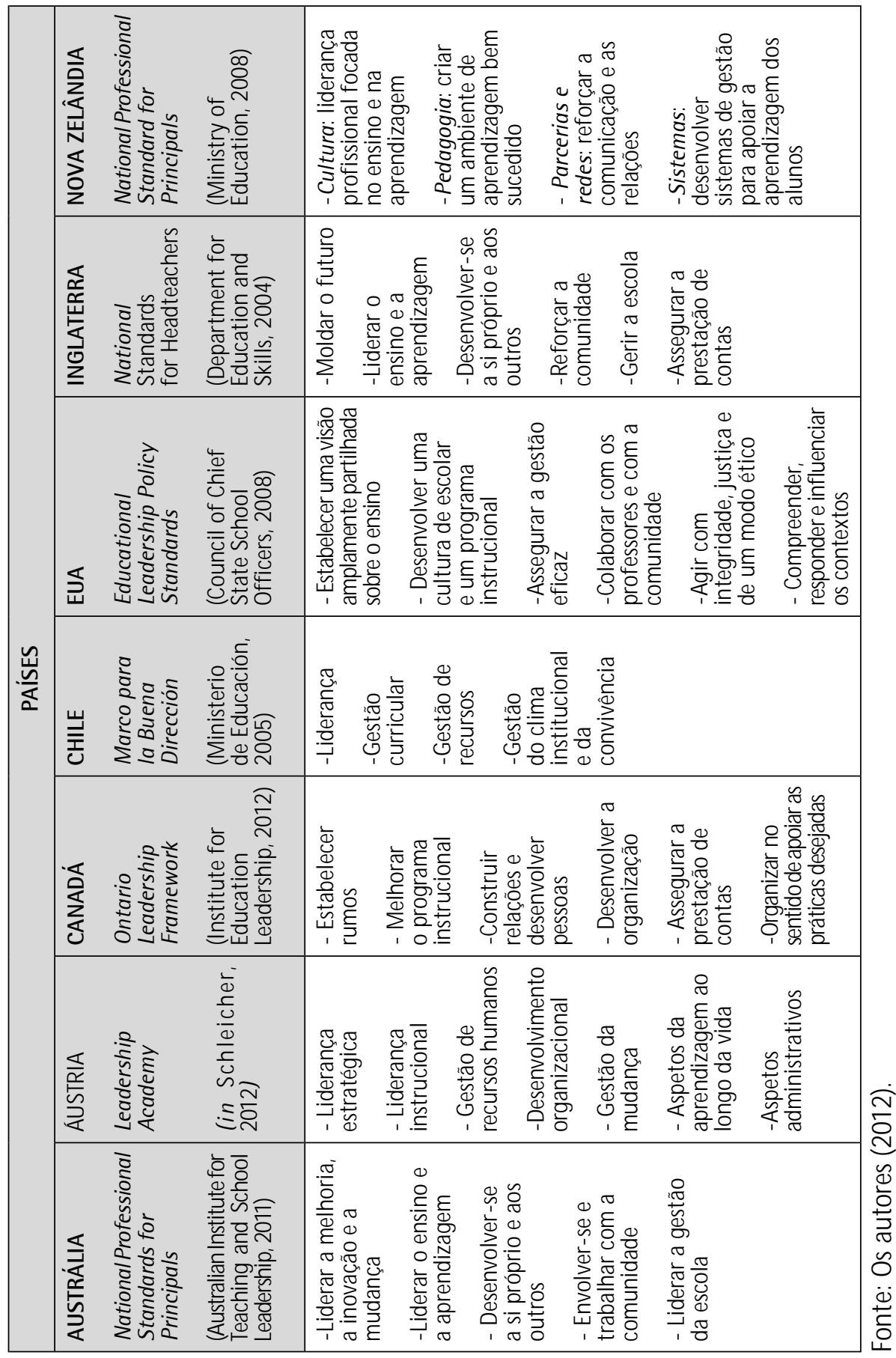


Para além da Áustria, Canadá (Ontário) e Inglaterra, outros países são normalmente invocados neste exercício de avaliação positiva da liderança escolar por parte da OCDE, tais como os Estados Unidos, o Chile e a Nova Zelândia.

No caso dos Estados Unidos, o quadro definidor dos padrões de liderança remonta a 1996, mas estesforam objeto de revisão em 2008: "Educational Leadership Policy Standards: ISLLC 2008" (COUNCIL OF CHIEF STATE SCHOOL OFFICERS, 2008, p. 18). Trata-se de um quadro concetual sobre o desempenho do gestor escolar no âmbito do qual, curiosamente, foi alterada a anterior designação de "school administrator" para "education leader". Também o Chile, pertencendo a um contexto geográfico e cultural "não inglês" e não europeu, apresenta um modo de liderança elogiado nos relatórios da OCDE, encontrando- se frequentemente associado ao conjunto de contextos nacionais positivos (PONT; NUSCHE; MOORMAN, 2008a). Em 2005, no Chile, foi colocada em marcha a medida "Marco para la Buena Dirección" que abrange quatro áreas de competência dos líderes: Liderazgo, Gestión curricular, Gestión de recursos e Gestión del clima institucional y convivencia. Um outro caso referido pela OCDE na área de práticas recomendáveis de liderança éa Nova Zelândia. 0 seu sistema educativo providencia uma organização bastante autónoma (um contexto próximo da autogestão para os diretores), o que lhe confere a posição primeira no domínio da gestão autonómica de recursos (PONT; NUSCHE; MOORMAN, 2008a, p. 53). As principaismedidas da Nova Zelândia para uma liderança bem-sucedida e implicada com o progresso do programa instrucional são as seguintes:

1) um programa formativo para os diretores em início de exercício do cargo;

2) uma rede de trabalho eletrónica para diretores/gestores ("LeadSpace");

3) centros de desenvolvimento para diretores em exercício ("Principals' Development Planning Centre");

4) orientações para o desenvolvimento profissional dos diretores (PONT; NUSCHE; MOORM AN, 2008a, p. 116).

Os quadros de referência ("Professional Standards for Principals") envolvem a participação do M inistério, das associações de diretores/administradores eoutras entidades.

0 quadro 1 dá-nos conta das principais dimensões que cada um destes países identificou como estruturadoras dos seus quadros de referência para o desempenho dos líderes escolares. Porém, uma análise mais pormenorizada dos documentos que suportam institucionalmente cada um destes cenários apresenta-nos um conjunto mais vasto de informações, com cada dimensão a desdobrar-se em especificações e descritores, tendo em conta a definição de uma matriz mapeadora do líder escolar eficaz.

Após a recolha abrangente e apreciação pormenorizada dos documentos institucionais de cada sistema educativo, e em jeito de meta-análise comparativa, sistematizámos os quadros de referência para a liderança educacional com indicação 
dos principais elementos caraterizadores (ver ANEXO) dos seguintes países: Austrália, Canadá, Chile, EUA, Inglaterra, Nova Zelândia (relativamente à Áustria, país referido no quadro 1, não foi possível recolher este tipo de informação).

A partir da meta-análise comparativa efetuada, verificou-se um conjunto variado, mas concetualmente aproximado, de dimensões e descritores de liderança educacional que nos permite apresentar uma sistematização em torno das seis seguintes dimensões fundamentais:

Orientação estratégica, visão e missão;

Processo de ensino e aprendizagem (liderança instrucional/pedagógica);

Relações interpessoais e desenvolvimento;

Organização e gestão de recursos;

Prestação de contas e responsabilização;

Relações com comunidade e contextos.

Apesar de algumas diferenças lexicais ou variação semântica, o conteúdo inerente a estas seis dimensões encontra-se, de um modo geral, presente nas propostas dos países referidos. Na verdade, as narrativas empregadas em cada um dos quadros de referência são similares nos vários contextos geográficos, o que, à partida, aponta para a existência de políticas educativas equivalentes neste domínio. Apesar do levantamento e sistematização realizados (ver ANEXO), não é nossa intenção proceder aqui a uma leitura crítica individualizada dos quadros de referência para o desempenho dos líderes escolares em função e cada contexto analisado. Contudo, se são notórias as similitudes semânticas encontradas nas dimensões em apreciação, uma revisão mais profunda de cada contexto, com a integração de elementos sociopolíticos e organizacionais, poder-nos-á dar conta das especificidades que naturalmente existirão.

\section{Considerações finais}

O levantamento exploratório que realizámos neste trabalho sobre liderança educacional e respetivos quadros de referência, tendo como suporte alguns dos trabalhos publicados pela OCDE nesta matéria, trouxeram para a ribalta um conjunto de países em que um dos traços comuns (à exceção do Chile) é o de serem países de língua inglesa. Se a Inglaterra tem sido considerada um dos países com tradição no investimento (político, mas também de investigação) na liderança escolar, não podemos desprezar o poder do discurso na língua inglesa como fator de "contaminação" das reformas que outros países foram realizando. Na verdade, a tradição e a língua constituíram fatores para que o sistema educacional britânico fosse um dos mais apontados entre os casos de estudo selecionados pela OCDE (M OLLER; SCHRATZ, 2008).

No quadro dos países anglófonos, também nosE.U.A., a aliança entrea liderança escolar e o aperfeiçoamento académico tornou-se o mote das políticas educacionais, com a liderança 
educacional a ser considerada, desde a década de oitenta, mais importante do que a gestão administrativa (YOUNG; GROGAN, 2008). Isto levou a que as suas políticas educativas se focassem em programas de pendor mais instrucional para os potenciais líderes educacionais. Relativamente ao Canadá, não obstante ter aderido a um certo perfil americano, tem vindo a dar mais atenção a uma estratégia de desenvolvimento de lideranças que tenha em conta os valores culturais, os métodos diversificados e a inclusão, tendo em conta a variedade de culturas que percorre 0 interior das escolas (EIITHWOOD, 2012, p. 13 - 21).

Sobre outros contextos geográficos, há que ter em conta a história dos sistemas educativos e das lideranças políticas (das mais autoritárias às mais democráticas), como é 0 caso da Europa face ao contexto americano, onde países com tradição mais centralizadora apresentam custos mais elevados no desenvolvimento da proclamada autonomia (MOLLER; SCHRATZ, 2008). A Áustria apresenta-se como um dos casos europeus referidosnestetrabalho em que a centralização e história da democracia condicionaram uma liderança educacional autónoma. Na verdade, apesar de mudanças recentes nas políticas educativas, continua presente a estandardização de métodos educacionais numa linha mais centralizadora (MOLLER; SCHRATZ, 2008, p. 345). Também o Chile, apesar de não ser um país de língua inglesa, encontra-sebem posicionado, ao lado de países como Inglaterra eÁustria, nas análises da OCDE no diagnóstico positivo relativamente às práticas de liderança eficaz.

Pode-se, assim, inferir que, de um modo geral, os casos apresentados adotam, em termos de liderança educacional, medidas políticas similares, como a que diz respeito à def inição, em cada um destes países, de quadros de referência para o desempenho dos líderes escolares, a questão que assumimos como central na incursão exploratória efetuada. Estes instrumentos - fundamentais para a definição, formação, seleção, regulação, avaliação e supervisão dos gestores escolares - constituem mecanismos estratégicos de operacionalização de políticas educativas no setor da administração e gestão das escolas, em particular no que diz respeito à liderança educacional e ao papel de relevo que deverá assumir na qualificação das organizações educativas.

\section{Referências}

COSTA, J. A. Liderança nas organizações: revisitando teorias organizacionais num olhar cruzado sobre as escolas. In: COSTA, J.; MENDES, A.; VENTURA, A. (Orgs). Liderança e estratégia nas organizações escolares. Aveiro: Ed. Universidade de Aveiro, 2000, p. 15-33.

. Imagens organizacionais da escola. Porto: ASA, 2003.

COUNCIL OF CHIEF STATE SCHOOL OFFICERS. Educational leadership policy standards: ISLLC 2008: as adopted by the National Policy Board for Educational Administration. Washington, 2008. Disponível em: <http://www.ccsso.org/Documents/2008/ Educational_Leadership_Policy_Standards_2008.pdf>. Acesso em: 15 nov. 2012. 
INSTITUTE FOR EDUCATION LEADERSHIP. The Ontario leadership framework 2012: a school and system leader's guide to putting ontario's leadership framework into action. Ontario: Institute for Education Leadership, 2012. Disponível em: <http://www.hpedsb.on.ca/ec/services/hrss/talentdevelopment/Documents/ OntarioLeadershipFramework2012N.pdf >. Acesso em: 15 nov. 2012.

LEITHWOOD, K. The Ontario leadership framework 2012: with a discussion of the research foundations. Toronto: Institute for Education Leadership, 2012. Disponível em: <http://iel. immix.ca/storage/6/1345688978/Final_Research_Report_-_EN.pdf >. Acesso em: 15 nov. 2012.

MOLLER, J.; SCHRATZ, M. Leadership development in Europe. In: LUMBY, J. et al. (Org.). International handbook on the preparation and development of school leaders. New York: Routledge, 2008, p. 341-366.

PONT, B.; NUSCHE, D.; MOORMAN, H. Improving school leadership: policy and practice. v. 1. OECD Publishing, 2008a. Disponível em: <http://www.oecd.org/ education/preschoolandschool/44374889.pdf>. Acesso em: 8 nov. 2012.

. Improving school leadership: policy and practice. v. 2. OECD Publishing, 2008b. Disponível em: <http://www.oecd.org/education/preschoolandschool/44375122. pdf>. Acesso em: 8 nov. 2012.

PRICE WATERHOUSE COOPERS. Independent study of school leadership. England, 2007. Disponível em: <http://www.cfbt.com/lincolnshire/pdf/latest\%20summary\%20 of $\% 20$ pcw \%20J an\%2007.pdf>. Acesso em: 13 ag. 2012.

ROYAL ROADS UNIVERSITY. The school leadership studies. Canada, [2012]. Disponível em: <http://leadership.school.royalroads.ca/>. Acesso em: 10 out. 2012.

SCHLEICHER, A. Preparing teachers and developing school leaders for the 21st century: lessons from around the world. OECD Publishing, 2012. Disponível em: <http://www.oecd.org/site/eduistp2012/49850576.pdf>. Acesso em: 22 nov. 2012.

TOMÁS, I.; COSTA, J . A. Avaliação de professores nas escolas públicas portuguesas. Ensaio: avaliação e políticas públicas em educação, Rio de Janeiro, v. 19, n. 72, p. 457- 484, 2011.

YOUNG, M.; GROGAN, M. Leadership preparation and development in North America. In: LUM BY, J. et al. (Org.), International handbook on the preparation and development of school leaders. New York: Routledge, 2008, p. 303-324.

Recebido em: 07/01/2013

Aceito para publicação em: 06/03/2013 


\section{Anexo}

Síntese comparativa dos quadros de referência para o desempenho dos líderes escolares

\begin{tabular}{|c|c|c|c|c|c|}
\hline \multirow{6}{*}{ 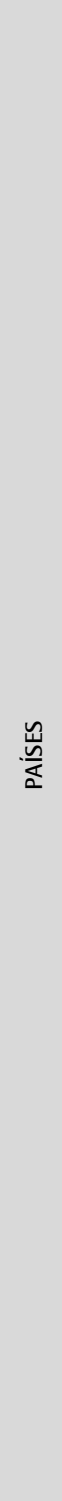 } & 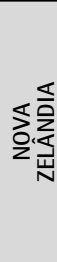 & 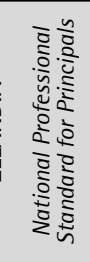 & 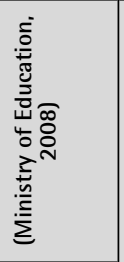 & \multirow{6}{*}{ 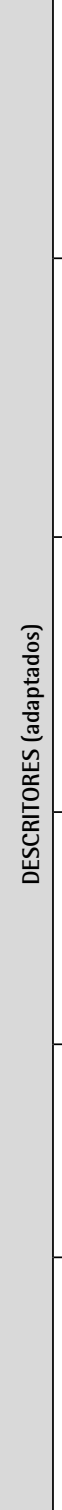 } & 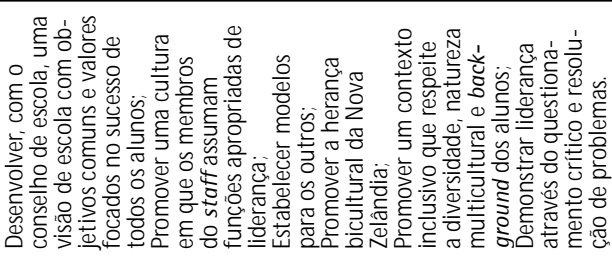 \\
\hline & 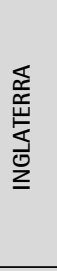 & 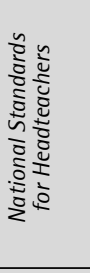 & 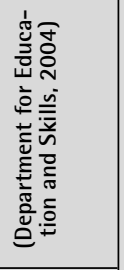 & & 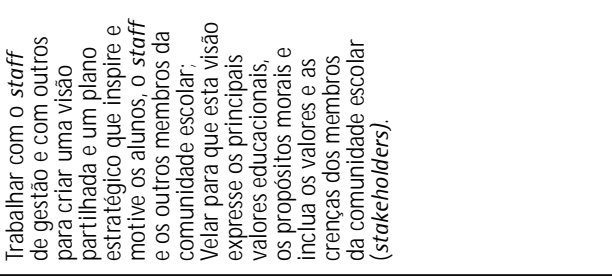 \\
\hline & $\lesssim$ & 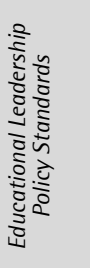 & 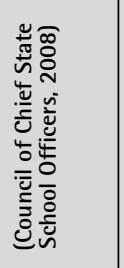 & & 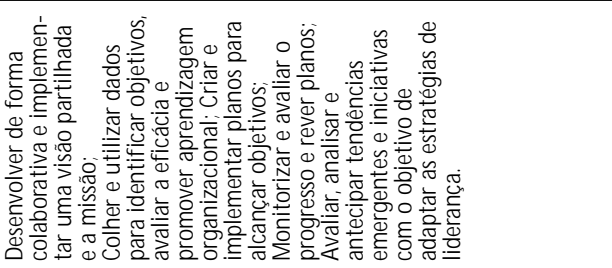 \\
\hline & $\stackrel{m}{\stackrel{\bar{\Xi}}{\rightleftarrows}}$ & 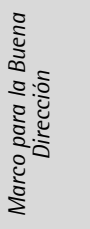 & 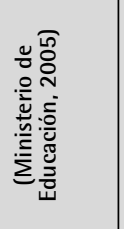 & & 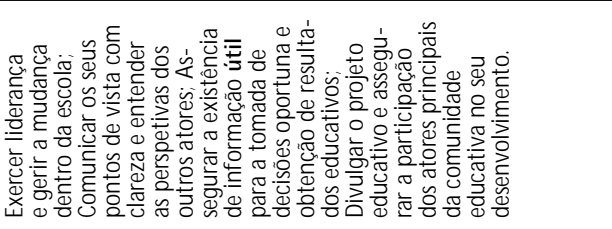 \\
\hline & 赵 & 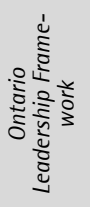 & 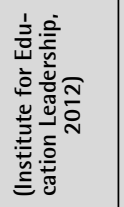 & & 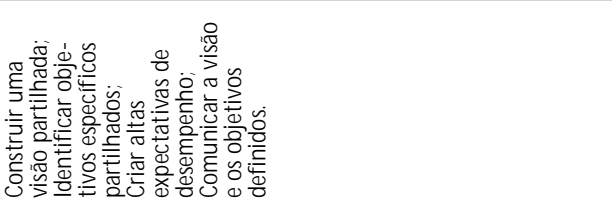 \\
\hline & 衣 & 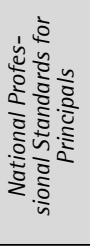 & 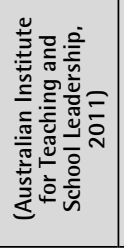 & & 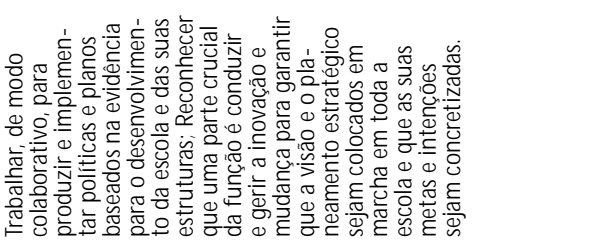 \\
\hline & & & 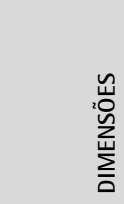 & & 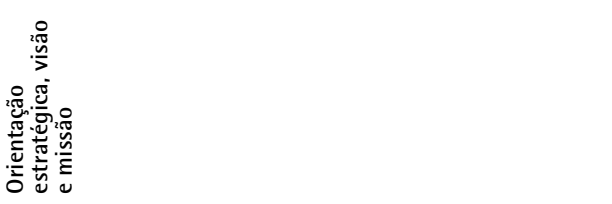 \\
\hline
\end{tabular}




\section{(Continuação)}
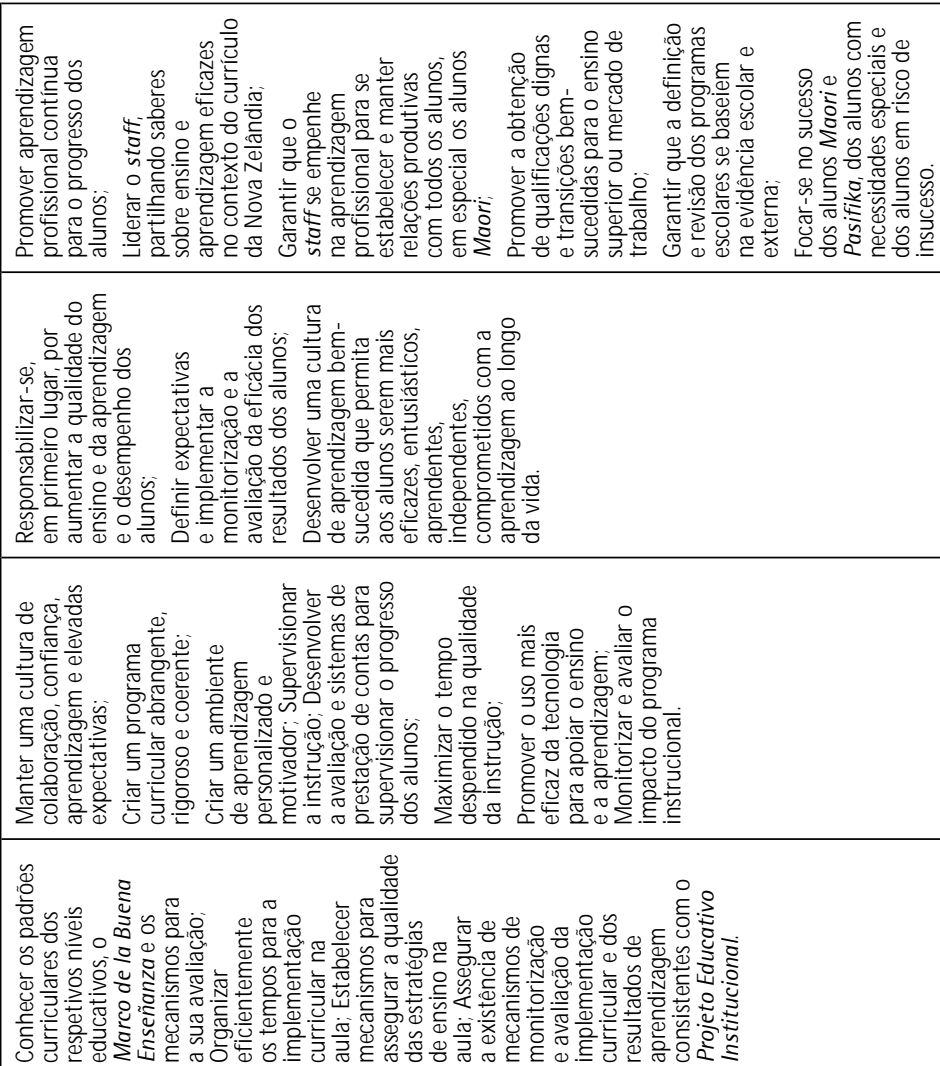

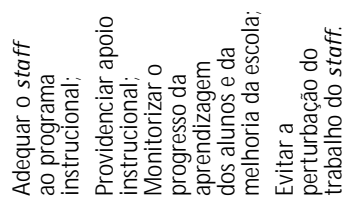
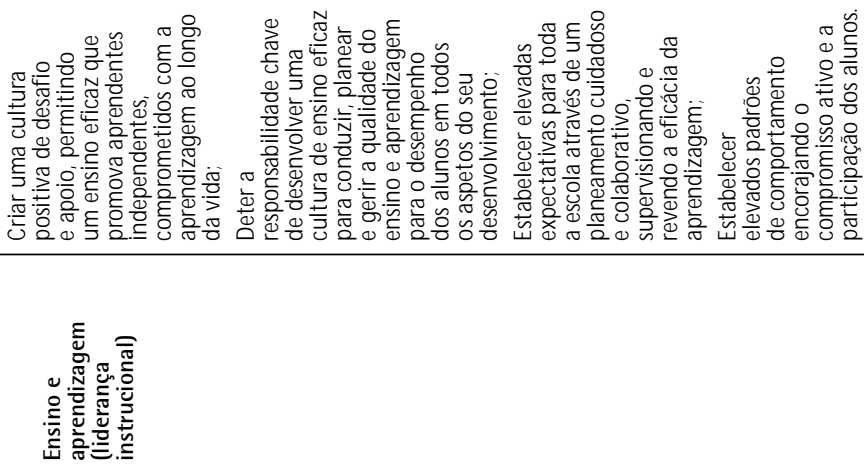


\section{(Continuação)}
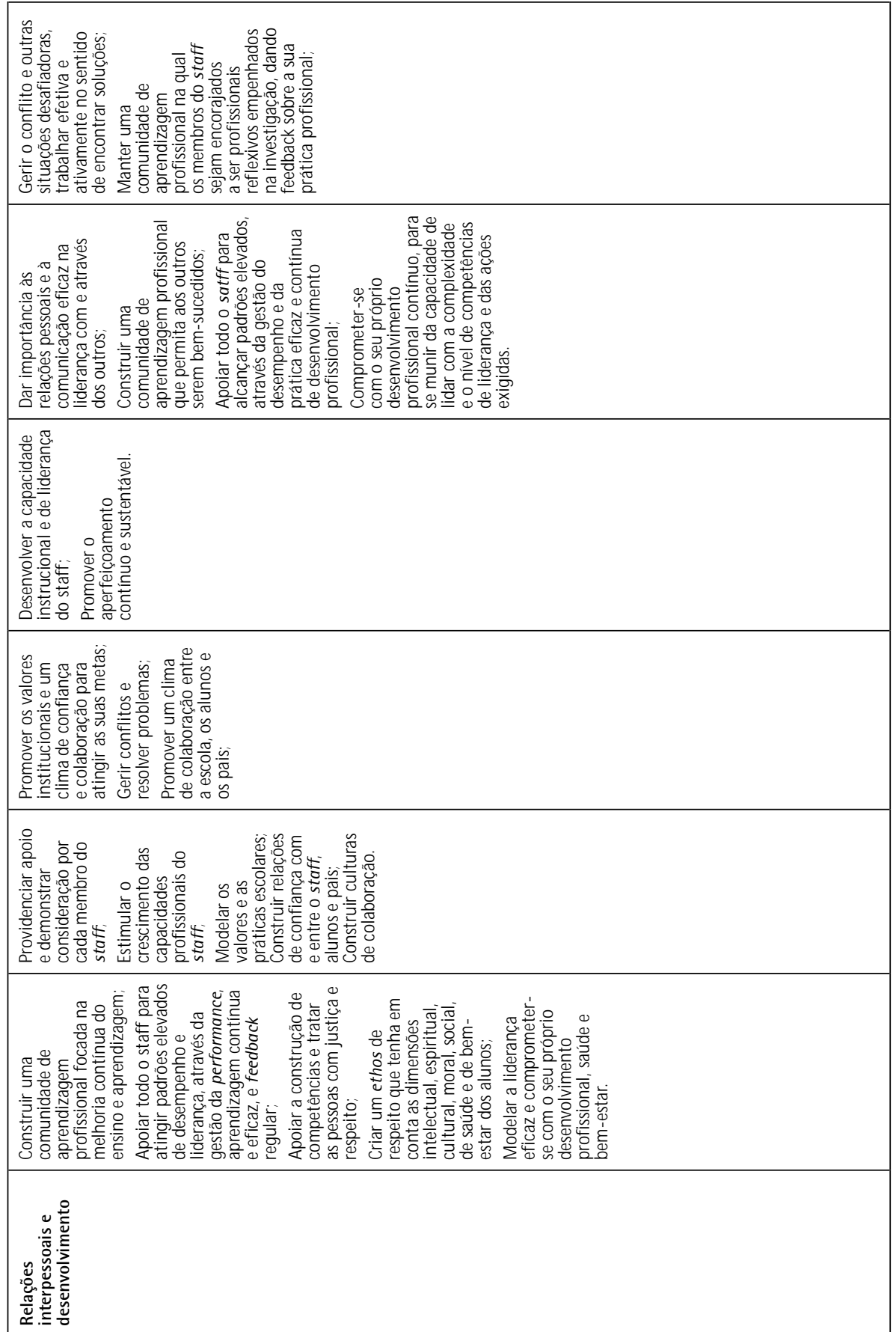


\section{(Continuação)}
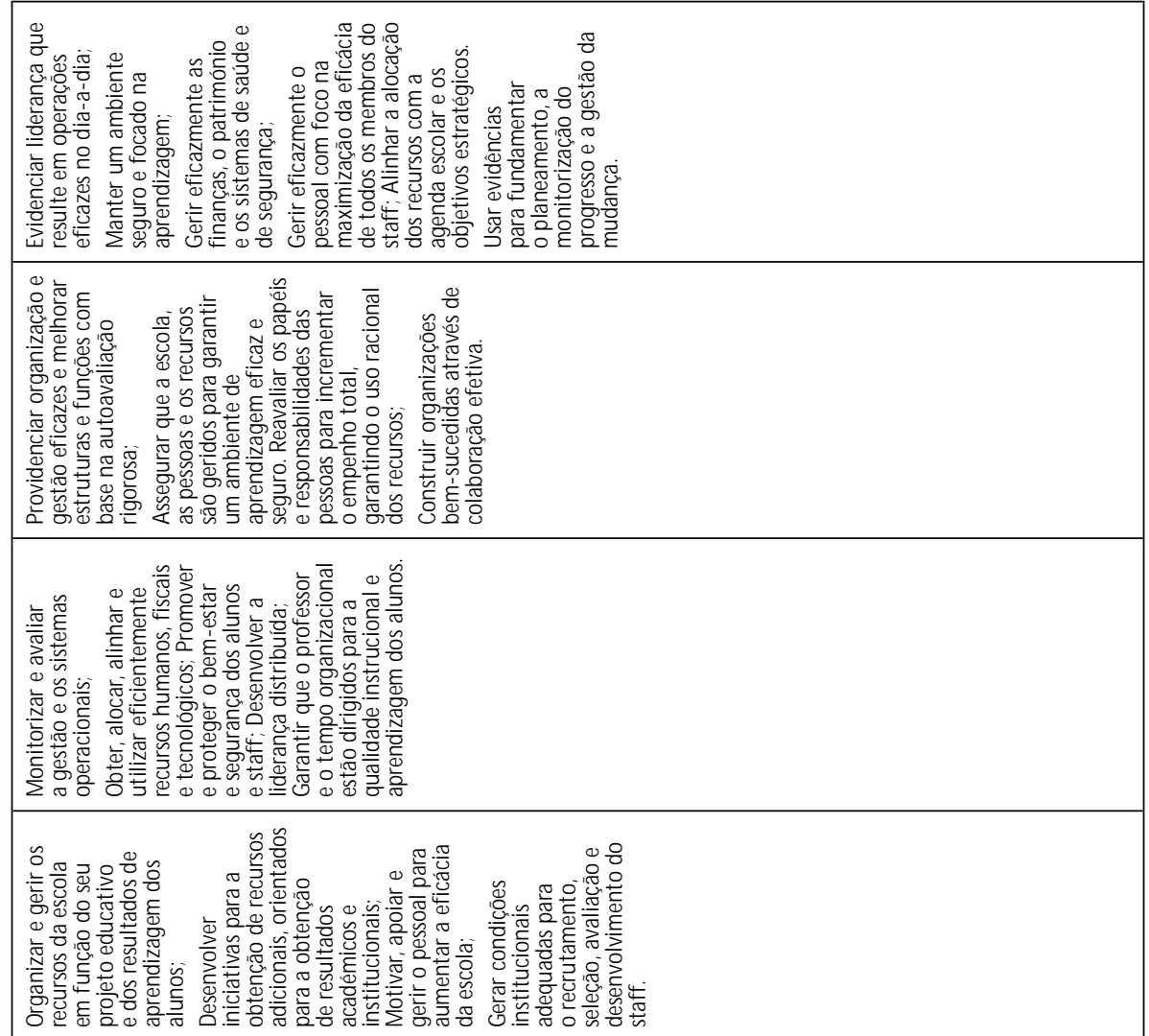

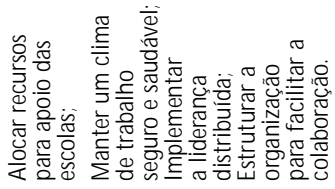

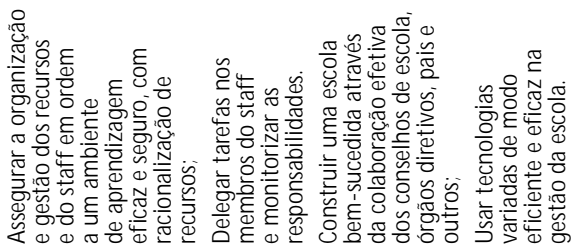

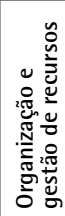




\section{(Continuação)}
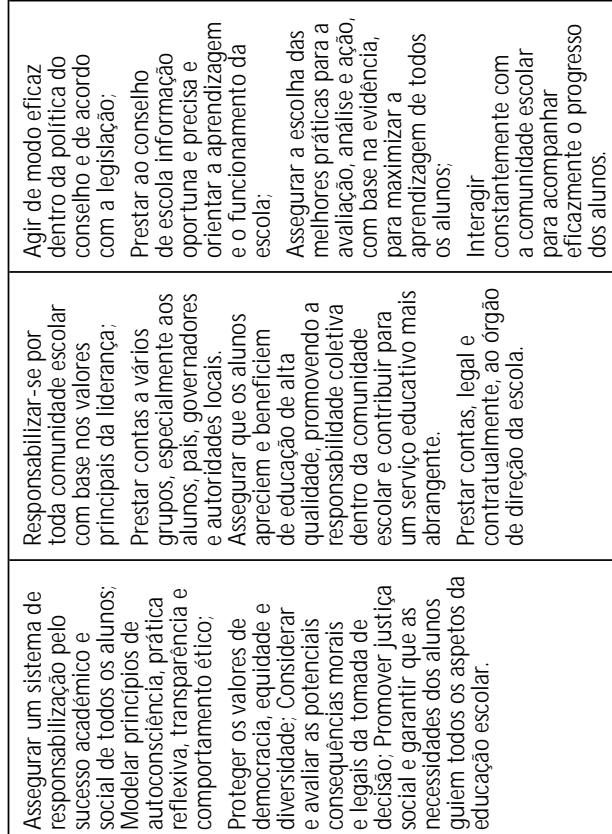

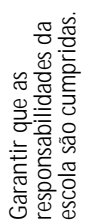

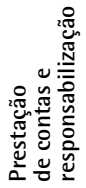




\section{(Continuação)}
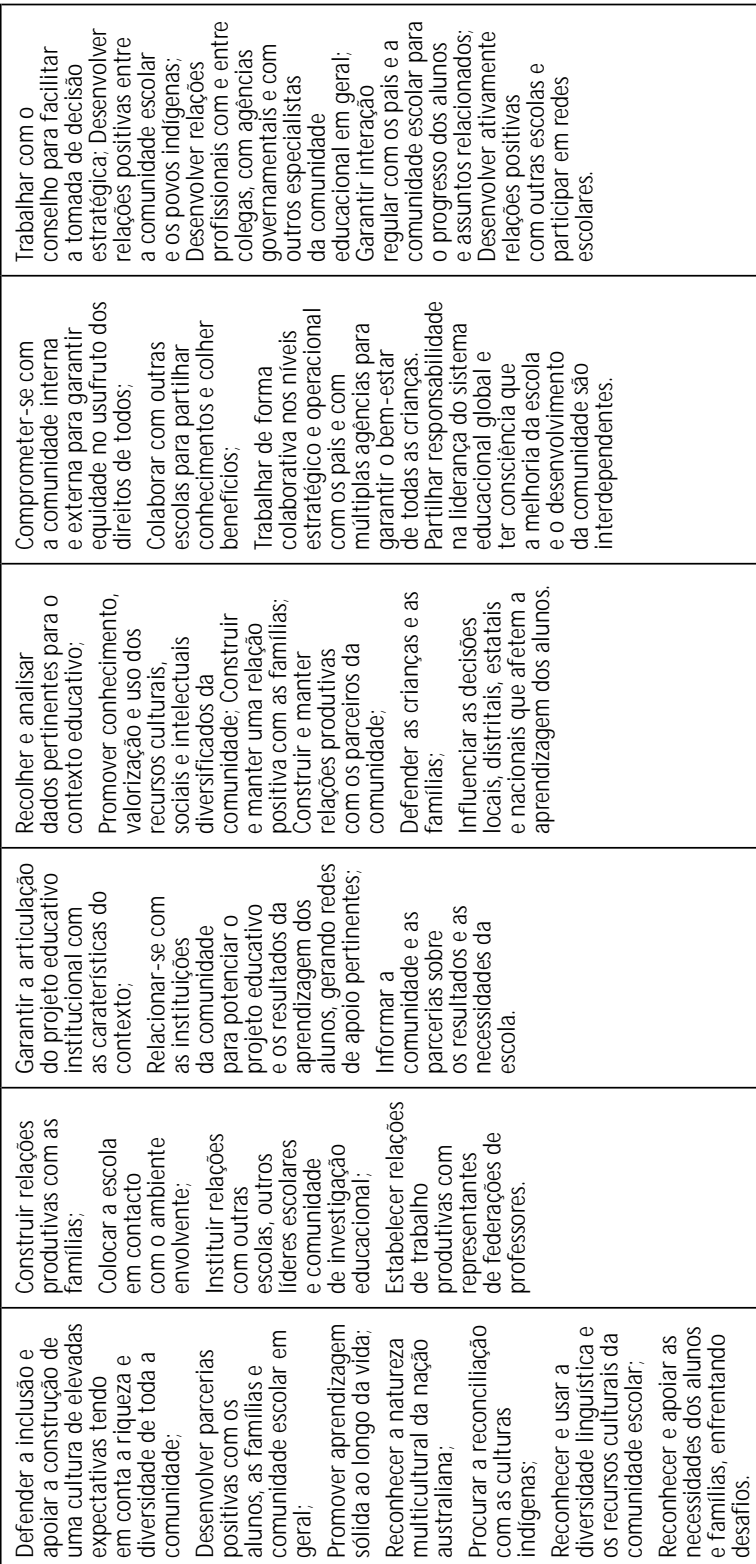

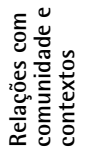

